\title{
Consumption of dietary supplements to support weight reduction in adults according to sociodemographic background, body mass index, waist-hip ratio, body fat and physical activity
}

\author{
Adrian Lubowiecki-Vikuk ${ }^{1 *}$ (D), Magdalena Król-Zielińska² ${ }^{2}$ and Adam Kantanista²
}

\begin{abstract}
Background: The aim of this study was to analyse the use of dietary supplements to support weight reduction (DSSWR) in adults according to sociodemographic background, body mass index (BMI), waist-hip ratio (WHR), body fat percentage (\%BF) and level of physical activity (PA).

Method: Participants $(n=1130)$ were recruited from a region of Poland with a high rate of adult overweight and obesity. Based on anthropometric data, BMI and WHR were calculated. \%BF was assessed using a bioimpedance method. To examine the association between DSSWR use and sociodemographic factors, BMI, WHR, \%BF and PA multiple logistic regression were conducted.

Results: The rate of DSSWR use in the group studied was high (69.5\%). A higher proportion of women, individuals aged 18-35 years, those who had completed higher education, those who did not report financial status as "poor", with a BMI < 18.5, normal \%BF and individuals with a high level of PA used DSSWR. In complete case analysis $(n=$ 1108), primarily financial status reported as "good" (OR $=2.18,95 \% \mathrm{Cl}: 1.69,2.81)$ or "hard to say" $(\mathrm{OR}=2.41,95 \% \mathrm{Cl}$ : $1.86,3.12)$ (vs. "poor") and female sex ( $\mathrm{OR}=2.59,95 \% \mathrm{Cl}: 2.17,3.08)$ were associated with DSSWR intake.
\end{abstract}

Conclusion: It seems that primarily financial status and sex, but also age, education, and level of PA, have significance in DSSWR use in adults and may be considered when developing appropriate strategies for body weight management and health promotion.

Keywords: Weight management, Exercise, Overweight, Obesity, Poland

\section{Background}

A well-balanced diet, combined with physical activity (PA), seems to be the appropriate method of maintaining a healthy body weight [1]. However, many adults use dietary supplements, considering them to be part of a well-rounded approach to body weight management [2]. Despite the lack of compelling evidence for any significant impact of supplement use on weight reduction [3-7],

\footnotetext{
* Correspondence: adrian.lubowiecki-vikuk@sgh.waw.pl

${ }^{1}$ Department of Consumer Behaviour Research, Collegium of Management and Finance, Warsaw School of Economics, Al. Niepodległości 162, 02-554 Warsaw, Poland

Full list of author information is available at the end of the article
}

supplements are becoming increasingly popular [8-11]. In the USA, more than $60 \%$ of the adult [12] and, in Australia, more than $70 \%$ of the university population [13] used a dietary supplement. The interest in dietary supplements supporting weight reduction (DSSWR) has been noted in Poland $[14,15]$, and also in other countries $[10,16]$.

The use of various dietary supplements may be associated with the nature of postmodern society, with its passive lifestyles, excessive consumption and medicalisation of the body, and pressure on individuals to maintain a healthy and attractive body [10,17-19]. The marketing activities of the pharmaceutical industry are also a factor of increase in dietary supplements use [20], despite

(C) The Author(s). 2019 Open Access This article is distributed under the terms of the Creative Commons Attribution 4.0 International License (http://creativecommons.org/licenses/by/4.0/), which permits unrestricted use, distribution, and 
known cases of the use of poor-quality production processes or the contamination of some supplements with prohibited substances [21]. Despite concerns of efficacy and safety, supplements are still used in weight management [7]. These supplements are advertised as requiring less effort than diet and exercise, with claims of effectiveness, are often cheap and are commonly available.

PA may be the cheapest way to reduce body weight, but is time-consuming and requires physical effort. Only the appropriate type, frequency and intensity of PA can reduce body weight in people of different ages [22, 23]. The use of DSSWR may be considered either a substitute for, or complement to, PA and a reduction of caloric intake. It must, however, be noted that using DSSWR is less demanding than maintaining a diet and increasing PA [24].

The use of dietary supplements may be affected by demographic and sociocultural factors [12, 25, 26]. Most users of dietary supplements are female, older [27], and college- or university-educated. According to Pillitteri et al. [10], the use of DSSWR was more common among women, younger adults and individuals with less education and lower incomes. The results are inconclusive, however, because, according to other studies [28-31], dietary supplement use was positively associated with education, income and age. In addition, some studies have indicated a growing number of supplement users who were also physically active [29, 32, 33], especially among men and individuals above the age of 45 years [27]. In these studies, though, the types and level of PA were not reliably measured. Therefore, it seems that the set of determinants of DSSWR use is not yet fully known.

Efforts to reduce body weight concern, in particular, people who are overweight or obese. This phenomenon is growing because the prevalence of obesity all over the world has increased from $3.2 \%$ in 1975 to $10.8 \%$ in 2014 in men, and from 6.4 to $14.9 \%$ in women [34]. In Poland (population is over 38.4 million people), the trend of obesity prevalence in adults is also adverse, and its growth since 1975 is one of the largest in the world. In men, 3.6 million and, in women, 4.3 million are obese [34]. Weight management in underweight individuals is also prevalent [35], but the studies are limited. In Poland, $60.6 \%$ of underweight and $61.7 \%$ of overweight adults have attempted to lose weight during the last 6 months, and many of them used slimming preparations [11]. According to Kozłowska and Pol [36], the main reasons for using DSSWR in adults were aesthetic concerns (63.8\%), low self-esteem (48.3\%) and the fashion for slim body (29.3\%). People with excessive or deficient body weight are willing to change their body status because they may be dissatisfied with their weight and appearance. Body dissatisfaction has been observed in many women and men $[37,38]$.
Women usually wish to be thinner $[39,40]$. Dissatisfaction with body fat percentage (\%BF) and muscle tone is common in adult men [41], as well as the desire to lose weight as they get older [42].

Identification practice in DSSWR may be helpful in designing appropriate health programmes for weight management in different groups of people. Additionally, monitoring the consumption of DSSWR in various social groups gives the opportunity to take action to raise awareness of the risks arising from their abuse.

Therefore, the aim of this study was to analyse the use of DSSWR in adult people, with regard to sociodemographic background, body mass index (BMI), waist-hip ratio (WHR), \%BF and level of PA.

\section{Methods}

Participants and procedures

The study included 1130 participants (assumed error $3 \%$, typical choice $95 \%$ ), aged $18-70$ years $($ mean $=43.4$ years, standard deviation $=15.6$ years). The participants were from Świętochłowice in the Silesian Voivodeship, a town with one of the three highest rates of adult obesity in Poland [43].

The study was performed by trained and supervised interviewers (with a degree in Pharmacy), according to a predetermined plan, between March and April 2017. Respondents were recruited via a public call (posters hung on advertising columns belonging to the town hall) for volunteers aged 18 years and above. The research was carried out in two stages: (1) measurement of body weight and height, calculation of BMI and WHR, then \%BF evaluation, and (2) completion of a paper questionnaire regarding PA level, sociodemographic variables and DSSWR use. Anthropometric measurements were performed in a designated private location to ensure discretion and comfort.

\section{Use of dietary supplements supporting weight reduction, evaluation of sociodemographic characteristics and undertaking of physical activity}

To evaluate the use of dietary supplements, the participants were asked whether they had used any DSSWR in the previous 3 months: "yes" or "no" answers were possible. They listed the trade name of supplements they had used. Next, it was decided whether the given products were DSSWR.

The sociodemographic characteristics of the respondents included sex (female, male), age (three categories were analysed: $18-35$ years old, $36-60$ years old, older than 60 years), marital status (married or unmarried) and education (primary, vocational, secondary, higher). Additionally, respondents were asked "What is your financial status?". Response options were "good", "poor" or "hard to say". To evaluate the level of PA, the self- 
reported Polish version of the International Physical Activity Questionnaire-Short Form (IPAQ-SF) [44] was used. The IPAQ-SF was completed during face-to-face interview. Participants were asked to recall the type and duration of their physical activities in the last 7 days. Based on their data, the metabolic equivalent (MET) was calculated. The results were presented as an estimation of energy expenditure in metabolic equivalent (MET). The MET-min week ${ }^{-1}$ was calculated as follows: minutes of activity/day $\times$ days per week $\times$ MET value. From this continuous variable of total PA scores, the data were categorised according to the IPAQ scoring guidelines. Participants with a total PA of $<600$ MET-min week ${ }^{-1}$ were classified in the "low" category, 600-2999 METmin week $^{-1}$ in the "moderate" category, and $\geq 3000$ MET-min week ${ }^{-1}$ in the "high" category.

\section{BMI, WHR and \%BF}

Weight was measured using an Omron scale in light clothing (without shoes) to the nearest $0.5 \mathrm{~kg}$. Height was measured with an anthropometer to the nearest 0.5 $\mathrm{cm}$. The body height and weight of the participants were used to calculate BMI $\left(\mathrm{kg} / \mathrm{m}^{2}\right)$. BMI values below 18.5 indicated underweight, from 18.5 to 24.99 normal weight and 25 and over overweight. Waist circumferences were measured at the end of several consecutive natural breaths, at a level parallel to the floor, midpoint between the top of the iliac crest and the lower margin of the last palpable rib in the midaxillary line. Hip circumference was measured at a level parallel to the floor, at the largest circumference of the buttocks. The WHR was calculated by dividing waist circumference (in $\mathrm{cm}$ ) by hip circumference (in $\mathrm{cm}$ ). The recommendations for sex-specific cut-off points were $94 \mathrm{~cm}$ (men) and $80 \mathrm{~cm}$ (women) for increased disease risk and $102 \mathrm{~cm}$ (men) and $88 \mathrm{~cm}$ (women) for substantially increased risk. WHRs $>0.9$ in men and $>0.85$ in women denoted abdominal obesity [45].

An Omron Body Fat Analyzer model HBF-360 (Omron Healthcare, Inc., Vernon Hills, IL, USA) was used to measure body fat in men and women. The participants' height, weight, age and sex were entered into the analyser. While standing with their feet slightly apart, the participant grasped the grip electrodes and held the analyser in front of their body, with arms fully extended and parallel to the floor. Each assessment took less than $1 \mathrm{~min}$ to complete. Although the bioimpedance method is not as accurate as, for example, dual-energy X-ray absorptiometry [46], according to Malavolti et al. [47], it is considered to be a valid, non-invasive, inexpensive method of determining total and regional body composition. The most frequently used \%BF cut-off points for defining obesity ( $25 \%$ in men, $35 \%$ in women) were used $[48,49]$.

\section{Analysis of data}

The examined variables were either nominal (sex, marital status, education, financial status and use of DSSWR) or categorised (age category, BMI status, WHR status, $\% \mathrm{BF}$ content and PA level), and were presented by number and percentage distribution. First of all, the chisquare independence test was used to determine whether there were differences between the use and non-use of DSSWR (dependent, nominal, dichotomous variable) and each independent variable (sex, age, marital status, education, financial status, BMI status, WHR status, \%BF content and PA level). Next, for all significant associations, one-way logistic regression analyses were conducted in order to investigate the association between the use of DSSWR ("yes" classification) and then statistically significant factors were included in multiple logistic regression. The analysis to examine the association between use of DSSWR and the predictors was done based on data from 1108 participants, because not all (1.95\%) respondents completed all questions. The odds ratio (OR) was calculated with the confidence interval $(95 \% \mathrm{CI})$ which allows one to determine whether this association is statistically significant. An area under the ROC curve (AUC) was calculated to assess the prediction quality of the multifactor model. The threshold for statistical significance for the inclusion of an independent variable in a multiple regression model was set at $p$ value $<0.05$. All calculations were performed using Statistica 13.0 (StatSoft, Inc.).

\section{Results}

Detailed descriptive statistics of the examined variables are presented in Table 1. Out of all respondents, 69.5\% declared they used DSSWR (Table 1).

Among those people using DSSWR, most were women (65.4\%), aged 36-60 (43.1\%), were in a relationship (55.9\%), had a vocational education (34.3\%), assessed their own financial situation as "good" (68.6\%) and were overweight (50.9\%), based on their BMIs. Furthermore, among people using DSSWR, the percentage share of people with normal or above normal \%BF was equal, $30.3 \%$ undertook PA at a high level, 39\% at a moderate level and $30.7 \%$ at a low level. Table 1 also presents the differences between the use or non-use of DSSWR and all independent variables. There were significant differences between the use of DSSWR and sex ( $p$ value < $0.001)$, age category ( $p$ value $<0.001$ ), education ( $p$ value $<0.001$ ), financial status ( $p$ value $<0.001$ ), BMI status ( $p$ value $=0.007), \% \mathrm{BF}(p$ value $<0.001)$ and PA level $(p$ value $<0.001$ ).

The results of the one-way logistic regression and multiple logistic regression of the use of DSSWR for each significant independent variable are shown in Table 2. 
Table 1 Descriptive statistics of variables among respondents divided into use and no use of dietary supplements supporting weight reduction (DSSWR), and differences between use of DSSWR and independent variables

\begin{tabular}{|c|c|c|c|c|}
\hline \multirow[t]{3}{*}{ Variables } & \multirow{2}{*}{$\begin{array}{l}\text { All } \\
\text { subjects }\end{array}$} & \multicolumn{2}{|c|}{ Use of DSSWR } & \multirow{3}{*}{$\begin{array}{l}p \\
\text { value }\end{array}$} \\
\hline & & Yes & No & \\
\hline & $\%$ & $\%$ & $\%$ & \\
\hline
\end{tabular}

\begin{tabular}{|c|c|c|c|c|c|c|c|}
\hline \multicolumn{8}{|l|}{$\overline{\text { Sex }}$} \\
\hline Women & 628 & 55.5 & 513 & 65.4 & 114 & 33.1 & \multirow[t]{2}{*}{$<0.001$} \\
\hline Men & 502 & 44.5 & 272 & 34.6 & 230 & 66.9 & \\
\hline \multicolumn{8}{|l|}{ Age category } \\
\hline 18-35 years old & 422 & 37.4 & 319 & 40.6 & 103 & 29.9 & \multirow[t]{3}{*}{$<0.001$} \\
\hline 36-60 years old & 477 & 42.2 & 338 & 43.1 & 138 & 40.2 & \\
\hline Older than 60 years & 231 & 20.4 & 128 & 16.3 & 103 & 29.9 & \\
\hline \multicolumn{8}{|l|}{ Marital status } \\
\hline Married & 637 & 57.5 & 429 & 55.9 & 208 & 61.2 & \multirow[t]{2}{*}{0.103} \\
\hline Unmarried & 471 & 42.5 & 338 & 44.1 & 132 & 38.8 & \\
\hline \multicolumn{8}{|l|}{ Education } \\
\hline Higher & 263 & 23.4 & 228 & 29.2 & 34 & 10.0 & \multirow[t]{4}{*}{$<0.001$} \\
\hline Secondary & 345 & 30.8 & 259 & 33.2 & 86 & 25.3 & \\
\hline Vocational & 452 & 40.3 & 268 & 34.3 & 184 & 54.1 & \\
\hline Primary & 62 & 5.5 & 26 & 3.3 & 36 & 10.6 & \\
\hline \multicolumn{8}{|l|}{ Financial status } \\
\hline "Good" & 687 & 61.3 & 536 & 68.6 & 151 & 44.5 & \multirow[t]{3}{*}{$<0.001$} \\
\hline "Hard to say" & 275 & 24.6 & 206 & 26.4 & 69 & 20.4 & \\
\hline "Poor" & 158 & 14.1 & 39 & 5.0 & 119 & 35.1 & \\
\hline \multicolumn{8}{|l|}{ BMI status } \\
\hline Underweight & 54 & 4.8 & 47 & 6.0 & 7 & 2.0 & \multirow[t]{3}{*}{0.007} \\
\hline Normal & 478 & 42.3 & 338 & 43.1 & 140 & 40.7 & \\
\hline Overweight & 597 & 52.9 & 399 & 50.9 & 197 & 57.3 & \\
\hline \multicolumn{8}{|l|}{ WHR status } \\
\hline Normal & 967 & 86.4 & 677 & 86.9 & 289 & 85.3 & \multirow[t]{2}{*}{0.458} \\
\hline Abdominal obesity & 152 & 13.6 & 102 & 13.1 & 50 & 14.7 & \\
\hline \multicolumn{8}{|l|}{$\% \mathrm{BF}$} \\
\hline Normal & 512 & 45.5 & 389 & 49.9 & 123 & 35.8 & \multirow[t]{2}{*}{$<0.001$} \\
\hline Above & 613 & 54.5 & 391 & 50.1 & 221 & 64.2 & \\
\hline \multicolumn{8}{|l|}{ PA level } \\
\hline High & 293 & 25.9 & 238 & 30.3 & 54 & 15.7 & \multirow[t]{4}{*}{$<0.001$} \\
\hline Moderate & 432 & 38.2 & 306 & 39.0 & 126 & 36.6 & \\
\hline Low & 405 & 35.9 & 241 & 30.7 & 164 & 47.7 & \\
\hline Total & & 100 & 785 & 69.5 & 344 & 30.5 & \\
\hline
\end{tabular}

In women, an almost twice as high chance of using DSSWR was found (OR $=1.95,95 \%$ CI 1.71, 2.23) compared to men. People aged 18-35 years had a one and a half times higher chance of using DSSWR (OR $=1.47$, $95 \%$ CI 1.22, 1.76) than people from older age categories. In the group of people with higher education, there was
Table 2 Results of one-way logistic regressions and multiple logistic regression analysis of use of dietary supplements supporting weight reduction (DSSWR)

\begin{tabular}{|c|c|c|c|c|}
\hline \multirow[t]{3}{*}{ Variables } & \multicolumn{4}{|l|}{ Use of DSSWR } \\
\hline & \multicolumn{2}{|l|}{$\begin{array}{c}\text { One-way logistic } \\
\text { regressions }\end{array}$} & \multicolumn{2}{|c|}{ Multiple logistic regression } \\
\hline & OR $(95 \% \mathrm{Cl})$ & $\overline{p \text { value }}$ & OR $(95 \% \mathrm{Cl})$ & $p$ value \\
\hline \multicolumn{5}{|l|}{$\overline{\text { Sex }}$} \\
\hline Women & $1.95(1.71-2.23)$ & $<0.001$ & $2.59(2.17-3.08)$ & $<0.001$ \\
\hline \multicolumn{5}{|l|}{ Age category } \\
\hline 18-35 years old & $1.47(1.22-1.76)$ & $<0.001$ & $1.29(1.03-1.61)$ & 0.026 \\
\hline 36-60 years old & $1.16(0.97-1.38)$ & 0.096 & & \\
\hline \multicolumn{5}{|l|}{ Education } \\
\hline Higher & $3.12(2.30-4.25)$ & $<0.001$ & $1.67(1.14-2.44)$ & 0.008 \\
\hline Secondary & $1.40(1.10-1.79)$ & 0.007 & & \\
\hline \multicolumn{5}{|l|}{ Financial status } \\
\hline "Good" & $2.34(1.93-2.84)$ & $<0.001$ & $2.41(1.86-3.12)$ & $<0.001$ \\
\hline "Hard to say" & $1.97(1.57-2.47)$ & $<0.001$ & $2.18(1.69-2.81)$ & $<0.001$ \\
\hline \multicolumn{5}{|l|}{ BMI status } \\
\hline Underweight & $2.10(1.23-3.59)$ & 0.007 & & \\
\hline \multicolumn{5}{|l|}{$\% \mathrm{BF}$} \\
\hline Normal & $1.34(1.17-1.52)$ & $<0.001$ & & \\
\hline \multicolumn{5}{|l|}{ PA level } \\
\hline High & $1.76(1.41-2.19)$ & $<0.001$ & $1.43(1.11-1.86)$ & 0.006 \\
\hline
\end{tabular}

a more than three times higher chance of using DSSWR $(\mathrm{OR}=3.12$, 95\% CI 2.30,4.25), and in the group of people with secondary education, the odds ratio was 1.4 (95\% CI 1.10, 1.79). The "good" financial status of the respondents increased their chances of using DSSWR by more than twice $(\mathrm{OR}=2.34,95 \%$ CI 1.93, 2.84). A greater chance of using DSSWR was found among people who were underweight based on their BMI $(\mathrm{OR}=$ 2.10, 95\% CI 1.23, 3.59), had normal \%BF (OR = 1.34, $95 \%$ CI 1.17, 1.52) and undertook PA at a high level (OR = 1.76, 95\% CI 1.41, 2.19).

In the final step, a multiple logistic regression was carried out. All relevant factors were inserted into the logistic regression model. According to the model, the use of DSSWR was predicted by five variables: financial status, sex, PA level, age category and education.

The use of DSSWR was explained first by financial status and sex. People who did not specify their financial situation or declared it to be "good" were over two times more likely to use DSSWR (OR = 2.41, 95\% CI 1.86, 3.12 and $\mathrm{OR}=2.18,95 \%$ CI 1.69, 2.81, respectively). Women had a more than two and a half times greater chance of using DSSWR (OR $=2.59,95 \%$ CI 2.17, 3.08). In addition, a greater chance of using DSSWR was found among people undertaking $\mathrm{PA}$ at a high level $(\mathrm{OR}=$ 
1.43), from the youngest age category $(\mathrm{OR}=1.29)$ and with higher education $(\mathrm{OR}=1.67)$.

In order to determine the quality of the predictions for the use of DSSWR, based on the variables selected for the model, an AUC was also calculated and was found to be 0.821 , which means that the model was characterised by good discrimination.

\section{Discussion}

The aim of the study was to analyse the use of DSSWR in adults with regard to sociodemographic background, BMI, WHR, \%BF and PA. The rate of DSSWR use was high (69.5\%). The likelihood of using DSSWR was higher in women than in men, in individuals aged 18-35 than among older people, in those who had completed higher education than in the less educated, in those who declared with "good" and "hard to say" financial status than in those with "poor" financial status and in those performing a high level of PA than those doing moderate and low levels of PA.

Similar results were obtained by Pillitteri et al. [10], regarding sex (women vs. men) and age (25-34 years), but different regarding education and financial status. This may be due to the fact that the population they studied $(n=1444)$ mainly comprised individuals who had long and unsuccessfully tried to manage their body weight and had the wrong impressions about the supplements they were using [10]. Another profile of American DSSWR users $(n=9403)$ was performed by Blanck et al. [2]. They found that women were more likely to use DSSWR than men, especially when considering the age bracket (18-35 years) and average income. Among men, the likelihood of DSSWR use was higher in younger individuals (18-35 years) who had completed higher education. Our results show that the chances of using DSSWR among adults primarily increase with financial status, and are higher among women, which refers to earlier research by Blanck et al. [50] and Machado et al. [51]. The result highlights the global trend of consumerism and socio-cultural women's attachment to the attractive appearance $[17,18]$. Subsequently, the chances of using DSSWR increase in relation to young people and those with higher education, which can be explained by the competences (knowledge and skills) of consumers [52].

In our study, the likelihood of DSSWR use was particularly high in those who engaged in high PA levels, and decreased among those with low PA levels. It seems likely that the latter group may consider DSSWR to be a substitute for PA, while the former may use DSSWR to complement the PA and increase the effectiveness of their efforts to achieve the desired body shape. Associations between DSSWR use and PA have been demonstrated by Kofoed et al. [26], Blanck et al. [50] and Fassier et al. [53]. This suggests that PA may be treated as a complementary method to support the reduction of body weight (which is or is not excessive). Thompson and Thomas [27] indicated that an association between PA and DSSWR use was more commonly found among men choosing simple forms of PA, such as walking or cycling.

In our study, it was found that \%BF and BMI were significantly associated with DSSWR use, while WHR did not have statistical significance. Ultimately, when using the multiple logistic regression model, these factors did not matter. So far, the impact of \%BF on DSSWR use has been confirmed in metabolic studies, but only on specific products [54-56]. Regarding BMI, the evidence regarding the associations between DSSWR use and BMI is inconclusive $[2,4,6,10,29,36]$, and further investigations are warranted.

Analysing the association of DSSWR use with just a single factor may only provide explanatory results, rather than definitive ones, with regard to body weight management. Therefore, the inclusion of additional factors seems necessary. While estimating the likelihood of DSSWR use, PA levels should be considered, along with the subjects' financial standing, sex, age and education. Our findings clearly indicate that DSSWR use rates are higher among people, who declared with "good" and "hard to say" financial status, especially young and educated women. Although the use of DSSWR is associated with risky health-related behaviours, as emphasised in the literature on the subject $[3-7,21,57]$, it is interesting to note that DSSWR is used in combination with PA.

This study had several limitations. First, it only considered the current use of DSSWR among adults in the town of Swiętochłowice. More detailed data on the timing and frequency of using DSSWR should also be included. Second, PA was calculated using a selfassessment method; therefore, a subjective interpretation of the questions may have influenced the results. In addition, the IPAQ-SF may have overestimated the PA level [58]. The \%BF was estimated using an Omron BF306 body composition monitor. According to JenskySquires et al. [59], the \%BF output from Omron devices should be interpreted with caution.

The main strength of this paper was the inclusion of sociodemographic and anthropometric (BMI, WHR and $\% \mathrm{BF}$ ) factors and PA in explaining DSSWR use. Previous studies have predominantly examined the association between single factors and DSSWR use. Another strength of this study was the inclusion of a large study population. The direct measurements of weight and height, and waist and hip circumference used in our research allowed for accurate BMI and WHR calculations. Despite some limitations concerning the measurement of \% BF using bioimpedance, the use of an objective method with such a large sample may be considered to be a strength of the study. 


\section{Conclusion}

It seems that primarily financial status and sex, but also age, education and level of PA, have significance in DSSWR use in adults and may be considered when developing appropriate strategies for body weight management and health promotion. This should allow public authorities at various levels to coordinate their sectoral activities and implement a cohesive health policy that also includes PA.

Due to the widespread use of DSSWR, these findings appear relevant not only for nutrition specialists, but also for health promoters and employees of sports and fitness clubs, who should pay particular attention to physically active patients/clients with the listed sociodemographic characteristics, and increase these patients'/ clients' awareness of the risks involved in DSSWR use.

\section{Abbreviations}

\%BF: Percent body fat; BMI: Body mass index; DSSWR: Dietary supplements supporting weight reduction; PA: Physical activity; WHR: Waist-hip ratio

\section{Acknowledgements}

The authors would like to thank Dominika Mucha (MPharm), who contributed to the data acquisition.

\section{Authors' contributions}

AL- $V$ prepared the study design, searched the literature, wrote the discussion of the study, gathered the necessary data, prepared it for analysis and prepared the manuscript. MK-Z refined the data, performed the statistical analysis and described its results. AK searched the literature, wrote the background of the study and corrected and improved the manuscript of the study for the final version. All authors have read and approved the final manuscript.

\section{Funding}

This research study received no specific funding. Salaries of the team members were provided by the employing institutions.

\section{Availability of data and materials}

The datasets used and analysed during the current study are available from the corresponding author on reasonable request.

\section{Ethics approval and consent to participate}

The study protocol was approved by the Local Bioethical Committee of the Karol Marcinkowski University of Medical Sciences (decision no. 399/18). All participants took part in the study voluntarily and were informed that they could discontinue their involvement at any time.

\section{Consent for publication}

The manuscript does not contain any individual person's data in any form.

\section{Competing interests}

The authors declare that they have no competing interests.

\section{Author details}

${ }^{1}$ Department of Consumer Behaviour Research, Collegium of Management and Finance, Warsaw School of Economics, Al. Niepodległości 162, 02-554 Warsaw, Poland. ${ }^{2}$ Department of Physical Education and Lifelong Sports, Poznan University of Physical Education, Królowej Jadwigi 27/39, 61-871 Poznań, Poland.
Received: 12 June 2019 Accepted: 9 October 2019

Published online: 05 November 2019

\section{References}

1. Drapier E, Brun JF, Fedou C, de Mauverger ER. Synergy between the slimming effects of exercise targeted at the LIPOXmax and diet moderately enriched in egg protein. Sci Sports. 2016;31(2):103-6. https://doi.org/10. 1016/j.scispo.2016.02.004

2. Blanck HM, Serdula MK, Gillespie C, Galuska DA, Sharpe PA, Conway JM, et al. Use of nonprescription dietary supplements for weight loss is common among Americans. J Am Diet Assoc. 2007;107(3):441-7. https://doi. org/10.1016/j.jada.2006.12.009.

3. Dwyer JT, Allison DB, Coates PM. Dietary supplements in weight reduction. J Am Diet Assoc. 2005;105(5):80-6. https://doi.org/10.1016/j.jada.2005.02.028.

4. Egras AM, Hamilton WR, Lenz TL, Monaghan MS. An evidence-based review of fat modifying supplemental weight loss products. J Obes. 2011;2011: 297315. https://doi.org/10.1155/2011/297315.

5. Onakpoya IJ, Wider B, Pittler MH, Ernst E. Food supplements for body weight reduction: a systematic review of systematic reviews. Obes. 2011; 19(2):239-44. https://doi.org/10.1038/oby.2010.185.

6. Pittler MH, Ernst E. Dietary supplements for body-weight reduction: a systematic review. Am J Clin Nutr. 2004;79(4):529-36. https://doi.org/10. 1093/ajcn/79.4.529.

7. Sharpe PA, Granner ML, Conway JM, Ainsworth BE, Dobre M. Availability of weight-loss supplements: results of an audit of retail outlets in a Southeastern City. J Am Diet Assoc. 2006;106(2):2045-51. https://doi.org/10. 1016/j.jada.2006.09.014.

8. Cerbone O, Vicedomini L, Formicola M, Colantuoni A. Dietary supplements and weight loss. Prog Nutr. 2011;13(2):81-90.

9. de Oliveira AB, Mapurunga JN, Melo MCA. Thermocenic supplements consumption and its side effects on customers of a sports nutrition shop in Fortaleza-CE. RBNE. 2017;11(62):160-7.

10. Pillitteri $J$, Shiffman S, Rohay JM, Harkins AM, Burton SL, Wadden TA. Use of dietary supplements for weight loss in the United States: results of a national survey. Obes. 2008;16(4):790-6. https://doi.org/10.1038/oby. 2007.136.

11. Sadowska J, Szuber M. The estimation of weight-loss programmes and using of slimming preparations among young women. Rocz Panstw Zakl Hig. 2011;62(3):343-50.

12. Dickinson A, Mackay D. Health habits and other characteristics of dietary supplement users: a review. Nutr J. 2014;13:14. https://doi.org/10.1186/14752891-13-14.

13. Barnes K, Ball L, Desbrow B, Alsharairi N, Ahmed F. Consumption and reasons for use of dietary supplements in an Australian university population. Nutr. 2016;32(5):524-30. https://doi.org/10.1016/j.nut.2015.10.022.

14. Cichocka I, Krupa J. The preferences in selecting dietary supplements used in slimming. Pol J Publ Health. 2016;126(4):170-4. https://doi.org/10.1515/ pjph-2016-0035.

15. Zegan M, Michota-Katulska E, Styczen M. Prevalence of the use of dietary supplements for weight loss in a selected group of female students. Hum Nutr Metab. 2015;42(4):229-38.

16. Valentine AA, Schumacher JR, Murphy J, Ma YJ. Dietary supplement use, perceptions, and associated lifestyle behaviors in undergraduate college students, student-athletes, and ROTC cadets. J Am Coll Heal. 2018;66(2):8797. https://doi.org/10.1080/07448481.2017.1377205.

17. Gracia-Arnaiz M. Fat bodies and thin bodies. Cultural, biomedical and market discourses on obesity. Appetite. 2010;55(2):219-25. https://doi.org/ 10.1016/j.appet.2010.06.002.

18. Lubowiecki-Vikuk A. Participation in medical tourism versus physical activity of patients after liposuction: what are the concerns about health and quality of life? Phys Cult Sport Stud Res. 2016;69(1):29-42. https://doi.org/10. 1515/pcssr-2015-0027.

19. Mansoubi M, Pearson N, Biddle SJ, Clemes S. The relationship between sedentary behaviour and physical activity in adults: a systematic review. Prev Med. 2014;69:28-35. https://doi.org/10.1016/j.ypmed.2014.08.028.

20. Kesselheim AS, Connolly J, Rogers J, Avorn J. Mandatory disclaimers on dietary supplements do not reliably communicate the intended issues. Health Aff. 2015;34(3):438-46. https://doi.org/10.1377/hlthaff.2014.0515.

21. Mathews NM. Prohibited contaminants in dietary supplements. Sports Health. 2018;10(1):19-30. https://doi.org/10.1177/1941738117727736. 
22. Clark JE. Diet, exercise or diet with exercise: comparing the effectiveness of treatment options for weight-loss and changes in fitness for adults (18-65 years old) who are overfat, or obese; systematic review and meta-analysis. J Diabetes Metab Disord. 2015;14:31. https://doi.org/10.1186/s40200-015-0154-1.

23. Osiński W, Kantanista A. Physical activity in the therapy of overweight and obesity in children and adolescents. Needs and recommendations for intervention programs. Dev. Period Med. 2017;21(3):224-34.

24. Saper RB, Eisenberg DM, Phillips RS. Common dietary supplements for weight loss. Am Fam Physician. 2004;70(9):1731-8.

25. Kantor ED, Rehm CD, Du M, White E, Giovannucci EL. Trends in dietary supplement use among US adults from 1999-2012. J Am Med Assoc. 2016; 316(14):1464-74. https://doi.org/10.1001/jama.2016.14403.

26. Kofoed CL, Christensen J, Dragsted LO, Tjønneland A, Roswall N Determinants of dietary supplement use - healthy individuals use dietary supplements. Br J Nutr. 2015;113(12):1993-2000. https://doi.org/10.1017/ S0007114515001440.

27. Thompson RL, Thomas DE. A cross-sectional survey of the opinions on weight loss treatments of adult obese patients attending a dietetic clinic. Int J Obes Relat Metab Disord. 2000;24(2):164-70.

28. Archer SL, Stamler J, Moag-Stahlberg A, Van Horn L, Garside D, Chan Q, et al. Association of dietary supplement use with specific micronutrient intakes among middle-aged American men and women: the INTERMAP study. J Am Diet Assoc. 2005;105(7):1106-14. https://doi.org/10.1016/j.jada. 2005.04.010

29. Bailey RL, Gahche JJ, Miller PE, Thomas PR, Dwyer JT. Why US adults use dietary supplements. JAMA Int Med. 2013;173(5):355-61. https://doi.org/10 1001/jamainternmed.2013.2299.

30. Block G, Jensen CD, Norkus EP, Dalvi TB, Wong LG, McManus JF, et al. Usage patterns, health, and nutritional status of long-term multiple dietary supplement users: a cross-sectional study. Nutr J. 2007;6:30. https://doi.org/ 10.1186/1475-2891-6-30.

31. Parnell JA, Reimer RA. Weight loss during oligofructose supplementation is associated with decreased ghrelin and increased peptide $Y Y$ in overweight and obese adults. Am J Clin Nutr. 2009;89:1751-9. https://doi.org/10.3945/ ajen.2009.27465.

32. Foote JA, Murphy SP, Wilkens LR, Hankin JH, Henderson BE, Kolonel LN. Factors associated with dietary supplement use among healthy adults of five ethnicities: the Multiethnic Cohort Study. Am J Epidemiol. 2003;157(10): 888-97.

33. Harrison RA, Holt D, Pattison DJ, Elton PJ. Are those in need taking dietary supplements? A survey of 21923 adults. Br J Nutr. 2004;91(4):617-23. https://doi.org/10.1079/BJN20031076.

34. NCD Risk Factor Collaboration. Trends in adult body-mass index in 200 countries from 1975 to 2014: a pooled analysis of 1698 population-based measurement studies with 19.2 million participants. Lancet. 2016;387(10026): 1377-96. https://doi.org/10.1016/S0140-6736(16)30054-X.

35. Choi O, Cho YG, Kang JH, Park HA, Kim KW, Hur Yl, et al. Weight control attempts in underweight Korean adults: Korea national health and nutrition examination survey, 2007-2010. Korean J Fam Med. 2013;34(6):393-402. https://doi.org/10.4082/kjfm.2013.34.6.393.

36. Kozłowska L, Pol P. Analysis of the use of supplements and foods supporting body mass reduction in a selected group of students. Probl Hig Epidemiol. 2013;94(3):626-9.

37. Fallon EA, Harris BS, Johnson P. Prevalence of body dissatisfaction among a United States adult sample. Eat Behav. 2014;15(1):151-8.

38. Frederick DA, Jafary AM, Gruys K, Daniels EA. Surveys \& the epidemiology of body image dissatisfaction. In: Cash TF, editor. Encyclopedia of body image and human appearance. San Diego: Academic Press; 2012. p. 766-73.

39. Assari S, Lankarani MM. The association between obesity and weight loss intention weaker among blacks and men than whites and women. J Racial Eth Health Disparities. 2015;2(3):414-20. https://doi.org/10.1007/ s40615-015-0115-x.

40. Swami V, Tran US, Stieger S, Voracek M. Associations between women's body image and happiness: results of the YouBeauty.com Body Image Survey (YBIS). J. Happiness Stud. 2015;16(3):705-18

41. Frederick DA, Essayli JH. Male body image: the roles of sexual orientation and body mass index across five national U.S. studies. Psychol. Men Masc. 2016;17(4):336-51. https://doi.org/10.1037/men0000031.

42. McCabe MP, Ricciardelli LA. Body image dissatisfaction among males across the lifespan: a review of past literature. J Psychosom Res. 2004;56(6):675-85. https://doi.org/10.1016/50022-3999(03)00129-6.
43. Central Statistical Office. Health and health care in 2016. Warsaw: GUS; 2017.

44. Biernat E, Stupnicki R, Gajewski A. International Physical Activity Questionnaire (IPAQ) - Polish version. Phys Educ Sport. 2007;51(1):47-54

45. World Health Organization. Waist circumference and waist-hip ratio: Report of a WHO expert consultation, Geneva, 8-11 December 2008. https:/apps.who. int/iris/bitstream/handle/10665/44583/9789241501491_eng.pdf;jsessionid=31 017A947F09469634F4386E93BC0F66? sequence=1. Accessed 10 Jan 2018.

46. Sillanpää E, Cheng S, Häkkinen K, Finni T, Walker S, Pesola A, et al. Body composition in 18- to 88-year-old adults - comparison of multifrequency bioimpedance and dual-energy X-ray absorptiometry. Obes. 2014;22(1):1019. https://doi.org/10.1002/oby.20583.

47. Malavolti M, Mussi C, Poli M, Fantuzzi AL, Salvioli G, Battistini N, et al. Crosscalibration of eight-polar bioelectrical impedance analysis versus dualenergy X-ray absorptiometry for the assessment of total and appendicular body composition in healthy subjects aged 21-82 years. Ann Hum Biol. 2003;30:380-91. https://doi.org/10.1080/0301446031000095211.

48. Deurenberg P, Andreoli A, Borg P, Kukkonen-Harjula K, De Lorenzo A, Van Marken Lichtenbelt WD, et al. The validity of predicted body fat percentage from body mass index and from impedance in samples of five European populations. Eur J Clin Nutr. 2001;55:973-9.

49. Okorodudu DO, Jumean MF, Montori VM, Romero-Corral A, Somers VK, Erwin PJ, et al. Diagnostic performance of body mass index to identify obesity as defined by body adiposity: a systematic review and metaanalysis. Int J Obes. 2010;34:791-9.

50. Blanck HM, Khan LK, Serdula MK. Use of nonprescription weight loss products: results from a multistate survey. JAMA. 2001;286(8):930-5.

51. Machado EC, da Silveira MF, da Silveira VFM. Prevalence of weight-loss strategies and use of substances for weight-loss among adults: a population study. Cad Saúde Pública. 2012;28(8):1439-49.

52. Dąbrowska A, Janoś-Kresło M. Dietary supplements and consumer rights. Wroclaw Econ. Rev. 2018;24(4):9-23. https://doi.org/10.19195/2084-4093.24.4.1.

53. Fassier $P$, Srour B, Raynard B, Zelek L, Cohen P, Bachmann P, et al. Fasting and weight-loss restrictive diet practices among 2,700 cancer survivors: results from the NutriNet-Santé cohort. Int J Cancer. 2018;143(11):2687-97. https://doi.org/10.1002/ijc.31646.

54. Kalman D, Colker CM, Wilets I, Roufs JB, Antonio J. The effects of pyruvate supplementation on body composition in overweight individuals. Nutr. 1999;15(5):337-40.

55. Smedman A, Vessby B. Conjugated linoleic acid supplementation in humans - metabolic effects. Lipids. 2001;36(8):773-81.

56. Ngondi JL, Etoundi BC, Nyangono CB, Mbofung CMF, Oben JE. IGOB131, a novel seed extract of the West African plant Irvingia gabonensis, significantly reduces body weight and improves metabolic parameters in overweight humans in a randomized double-blind placebo controlled investigation. Lipids Health Dis. 2009;8:7. https://doi.org/10.1186/1476-511X-8-7.

57. Chang YYC, Chiou WB. Taking weight-loss supplements may elicit liberation from dietary control. A laboratory experiment. Appetite. 2014;72:8-12. https://doi.org/10.1016/j.appet.2013.09.021.

58. Lee PH, Macfarlane DJ, Lam TH, Stewart SM. Validity of the international physical activity questionnaire short form (IPAQ-SF): a systematic review. Int J Behav Nutr Phys Act. 2011:8(1):115.

59. Jensky-Squires NE, Dieli-Conwright CM, Rossuello A, Erceg DN, McCauley S, Schroeder T. Validity and reliability of body composition analysers in children and adults. Br J Nutr. 2008;100(4):859-65. https://doi.org/10.1017/ S0007114508925460

\section{Publisher's Note}

Springer Nature remains neutral with regard to jurisdictional claims in published maps and institutional affiliations. 